\title{
Putting the public back in behavioral public policy
}

\author{
PATRICIA DE JONGE \\ Dutch Authority for the Financial Markets (AFM), Amsterdam, The Netherlands and Department of Marketing, \\ VU Amsterdam, Amsterdam, The Netherlands \\ MARCEL ZEELENBERG * \\ Tilburg Institute for Behavioral Economics Research, Tilburg, The Netherlands and Department of Marketing, \\ VU Amsterdam, Amsterdam, The Netherlands \\ PEETER W.J. VERLEGH \\ Department of Marketing, VU Amsterdam, Amsterdam, The Netherlands
}

\begin{abstract}
Behavioral public policies are aimed at influencing the behavior of the public in a way that is advantageous for the public itself and within the law. Sanders, Snijders and Hallsworth (2018, this issue) summarize the state of the art of this new field of study and introduce a number of challenges and opportunities for the time to come. We address an additional challenge that is present and central in all attempts to influence behavior, namely the public - the people that are the target of behavioral public policies. We review evidence revealing that people do not passively accept those influence attempts, but often show reactant responses. We propose that the Persuasion Knowledge Model provides a framework both to understand the reactions of the public and to facilitate communication between academic researchers and practitioners.
\end{abstract}

Submitted 11 December 2017; accepted 13 March 2018

Public policy may be conceptualized as the actions by which a government addresses the needs of its citizens. This includes the implementation of rules and regulations to ensure that the public does not engage in undesirable behaviors. Recent developments, primarily based on findings from the field of behavioral economics, take into account the fact that behavioral interventions might sometimes be more efficient than such traditional policy tools in achieving policy-makers' goals (Benartzi et al., 2017), hence the popularity of

* Correspondence to: Tilburg Institute for Behavioral Economics Research, Tilburg University, 5000 LE Tilburg, The Netherlands. Email: Marcel@uvt.nl 
behavioral public policy. The goal of behavioral public policy is influencing the behavior of the public in a way that is within the law and advantageous for the public itself. Sanders, Snijders and Hallsworth (2018) nicely summarize the state of the art of this new field of study and introduce a number of challenges and opportunities for the time to come. We would like to address another challenge that is present in all attempts to influence behavior; namely, the public that is the target of these interventions. Taking into account the public - the people that are going to be influenced by these policies - is crucial, as is evident from the fact that some interventions have proven to be less effective than expected beforehand. We will illustrate this later on using the recent proposed change of default in the organ donor laws in The Netherlands (Krijnen et al., 2018).

Our point is actually quite simple and straightforward. When one attempts to influence people's behavior, one should take into account that the people one is targeting have an opinion about this. In the fields of social psychology and marketing, theories have been developed to understand the reactions of people that are subjected to such influence attempts. We would like to briefly review these theories here, as we believe that people's reactions to influence attempts is an overlooked issue in behavioral public policy. In particular, attempts to influence behavior can trigger so-called 'reactance' in the person targeted. Reactance is the counter-response that can occur when people feel their freedom to behave, choose or think in a particular way is being threatened (Brehm, 1966). But as of now, very little is known about when and how behavioral public policy interventions trigger reactance. As the popularity of these interventions increases and their use spreads through governments, regulators and other agencies worldwide, improving our understanding of public responses is both important and timely.

Here, we make the case for putting the public back in behavioral public policy. We first look at reactance and what is known about reactance in relation to behavioral public policy interventions. We then propose that a wellknown theory from marketing research - the Persuasion Knowledge Model - has great potential for improving our understanding of public responses to behavioral policy interventions. We conclude by articulating several research questions that, in our opinion, should be high on the field's list of research priorities.

\section{Reactance theory}

Reactance is the well-known social psychological theory about how people react to threats of loss of freedom (Brehm, 1966; Brehm \& Brehm, 1981). When people expect freedom and they perceive that this freedom is being 
restricted, reactance can occur. In this context, threats to freedom should be interpreted broadly. They include flat-out restrictions and prohibitions, but also the pressure to behave, choose or think in a particular way. Think, for example, of a government trying to implement new consumer protection regulations (Clee \& Wicklund, 1980), an insurance provider limiting the number of product options available to a particular consumer or a parent pressuring his or her child to eat more vegetables. In the literature, reactance is treated both as a motivational state (Clee \& Wicklund, 1980), to be measured by looking at the outcome of a choice process or a combination of anger and negative cognitions (Rains, 2013), and as a trait (Jung \& Mellers, 2016) that can be measured directly.

As parents who have attempted to increase the vegetable intake of their offspring will be able to confirm, pressure to behave in a particular way does not necessarily increase enthusiasm about the desired behavior in the person being pressured. In fact, threats to freedom can lead a person to do the opposite of what was intended - the so-called boomerang effect (Clee \& Wicklund, 1980). The behavior shown by a person experiencing reactance is not primarily intended to be in line with this person's own preferences, but it is intended to regain a sense of control (Jachimowicz et al., 2017). This can even lead to people choosing options that are objectively worse than available alternatives (Jung \& Mellers, 2016).

\section{Reactance and behavioral public policy}

Several studies have looked at support for behavioral public policy interventions, particularly various types of nudges, in the USA and a number of European countries (Jung \& Mellers, 2016; Reisch \& Sunstein, 2016). These studies find that support for many nudges is fairly high, often higher than support for more traditional policy tools like taxes and prohibitions. Reisch and Sunstein (2016) found substantial differences between countries in terms of average levels of support. The same authors found no clear link between support for nudges and demographic variables and political orientation (with the exception of the USA). Jung and Mellers (2016) found that attitudes toward nudging are partly driven by individual dispositions. They found that empathetic people generally support nudges, while individualists and conservatives generally oppose them. Reactant people also expressed less support for nudges because they perceived them as autonomy threatening.

Crucially, due to their research design, Jung and Mellers (2016) were unable to disentangle attitudes toward nudging from attitudes toward underlying policy goals. Using a research design developed to do just this, Tannenbaum et al. $(2017$, p. 1) found a large partisan nudge bias in a series of experiments: 
they described this as "an instance of attribution substitution, where individuals evaluate the acceptability of a policy nudge by instead assessing how they feel about the associated policy objective or policy sponsor."

Reisch and Sunstein (2016) also concluded that people seem to have stronger opinions about the underlying policy goals than about the policy instruments. One puzzling example of this is their finding of significant support for subliminal advertising to discourage smoking and overeating - a nudge judged to be extremely inappropriate by the authors themselves - in many European countries.

While Tannenbaum et al.'s (2017) partisan nudge bias disappears when partisan cues are removed from the nudge description, the authors emphasized that removing all political context in real-world cases is simply impossible. Moreover, both experiences in the field and in the lab have shown that attempts to nudge can in fact lead to reactance. Let us provide some examples.

In late 2016, one of the chambers of the Dutch parliament passed a bill to change the system for organ donation in The Netherlands from opt in (you are not a donor until you register yourself as one) to opt out (presumed consent unless you explicitly indicate you do not want to be a donor). Even though the bill still needs to be approved by the other chamber before it becomes law, Krijnen et al. (2018, emphasis added) described how the bill and corresponding media attention led to reactance, even among people that had previously consented by explicitly opting in on a governmental website.

Remarkably, however, the month the bill passed the number of residents who explicitly registered as non-donors spiked to roughly 40 times the number found in previous months. This dramatic (albeit temporary) jump in active rejections was observed not only among newly registering residents, but also among those who had previously consented to donation and then went to the trouble of revoking their consent.

Reiter et al. (2012) examined consent for human papillomavirus (HPV) vaccines in the lab. The HPV vaccine for adolescents is controversial for many parents, and uptake of the vaccine has remained far below the levels recommended by health experts. Contrary to their own hypothesis, the researchers found that parents were more likely to agree to vaccination in the opt-in scenario than in the opt-out or neutral scenarios. Also in the lab, Hedlin and Sunstein (2016) found reactance to a green energy default when this option was more costly than 'regular' energy. And Arad and Rubinstein (2017) found that even when people support the underlying policy goals (e.g., saving more and eating more healthy foods), a significant proportion objected to the nudges used to achieve those policy goals. Concern about manipulation (in other words, reactance) seems to be an important driver of objection. 
That government regulations, even those with the best interests of the public at heart, could cause reactance was foreseen by reactance theorists (Clee \& Wicklund, 1980). Of course, one of the reasons nudges are so popular is that they are alternatives to more traditional policy tools like conventional regulation (e.g., rules on information disclosure) and they preserve nominal (although not necessarily effective) freedom of choice (Rebonato, 2014). In fact, Sunstein (2017) argued that reactance is rare and probably not a big issue in the case of nudges (in this particular case: defaults) because defaults preserve autonomy. But, as also argued by others (Clee \& Wicklund, 1980; Pavey \& Sparks, 2009; Jachimowicz et al., 2017), it is perceived autonomy that matters.

In other words, for reactance to occur, it is not necessary that freedom is actually limited. What is necessary, however, is that people experience some pressure to change (Clee \& Wicklund, 1980). Thus, for reactance to occur in the case of behavioral public policy interventions, people need only have the impression that someone is trying to influence their behavior. At present, the number of studies looking at the effect of transparency on nudging is still limited, particularly in field settings and for topics with relevance for public policy-makers. Moreover, the results so far have been inconclusive, probably as a result of various types of transparency being tested. Loewenstein et al. (2014), for example, found that transparency about the presence of defaults did not impact decision-making. Steffel et al. (2016) found that disclosing the intent of a nudge had no effect on the effectiveness of a default. Studies on the effect of disclosing the unconscious character of nudges on support show conflicting results (e.g., Felsen et al., 2013; Petrescu et al., 2016). And, as described previously, when Tannenbaum et al. (2017) disclosed the policy-maker doing the nudging, this had a large effect on nudge acceptance.

\section{Putting the public back in behavioral public policy}

Together, these observations demonstrate that it is important to keep in mind that behavioral public policy not only contains the word 'behavioral', but also the word 'public'. Put differently, when designing interventions, we should not forget the psychology of the people being influenced (for related arguments, see Jachimowicz et al., 2017; Krijnen et al., 2018).

Our observations in the previous sections also demonstrate that our understanding of the psychological reactions to behavioral public policy interventions is still limited, fragmented and lacking a coherent theoretical framework. This makes it very hard for policy-makers to distill practically relevant lessons. Additionally, it contributes to the gap between policy-makers and academia as identified by Sanders, Snijders and Hallsworth (2018). 
It may not be remarkable that in marketing and communication science, the importance of the psychology of the people being influenced has received ample attention. This has resulted in theoretical approaches that could help improve our understanding of when and why behavioral public policy interventions trigger reactance. In particular, the Persuasion Knowledge Model (PKM; Friestad \& Wright, 1994) offers a lot of potential, both for increasing our understanding of public reactions to influence attempts and for unifying insights that stem from various hitherto unrelated research programs.

\section{The potential of the Persuasion Knowledge Model}

The PKM states that how a person responds to a persuasion attempt is not only influenced by that person's knowledge about the topic at hand and the persuasion agent, but also by what Friestad and Wright (1994) refer to as that person's persuasion knowledge. Persuasion knowledge includes a person's beliefs about strategies and tactics used by a persuasion agent, the effectiveness and appropriateness of these tactics and the available response strategies. Topic, agent and persuasion knowledge interact to influence how someone copes with a persuasion attempt - although this interaction is in fact rarely studied (Campbell \& Kirmani, 2008).

The PKM is by no means a novel theory. Peter Wright coined the idea as far back as 1986 in his presidential address at the Association for Consumer Research conference $(1986$, p. 1$)$ :

Isn't it very plausible that people have intuitive theories about the tactics that are used in the game of marketplace selling-and-buying? They surely must have personal insights that are pertinent for realizing, "Aha! Somebody's scheming to sell me something! Somebody's trying to mind-screw me!", and for interpreting and evaluating and dealing with whatever influence tactics are being used. I'll call such an intuitive theory about marketers' influence tactics a "schemer schema."

In the same speech, Wright advocated shifting the research focus from persuasion agent to persuasion target; that is, the consumer. It does not require a great deal of imagination to see the relevance of Wright's intuitions, and their subsequent theoretical elaboration in the PKM, to the study of behavioral public policy and public reactions to interventions. Yet to the best of our knowledge, only one paper on nudges, by Steffel et al. (2016), explicitly refers to persuasion theory.

Steffel et al. (2016) use persuasion theory mainly to make the case for more transparency about the use of defaults. We think the usefulness of the PKM in the context of behavioral public policy is actually much greater. For example, applying the PKM to the work by Tannenbaum and colleagues (2017) clarifies 
that, when asked for their attitude toward an instrument of persuasion, people primarily apply their topic knowledge (or rather, beliefs) and agent knowledge (beliefs) in forming a judgment, rather than their knowledge of the persuasion strategies and tactics involved. To the extent that people do apply their persuasion knowledge - for example, when perceived effectiveness is an important driver of attitude to nudges (cf. Petrescu et al., 2016) - persuasion knowledge about behavioral public policy interventions seems limited and is often wrong. For example, many people seem to think that educational campaigns are more effective than changing defaults (Diepeveen et al., 2013; Jung \& Mellers, 2016).

These findings raise a number of interesting empirical questions for the study of reactions to behavioral public policy interventions that, as of now, remain unanswered. For example, is it possible to trigger accurate persuasion knowledge about behavioral public policy interventions? And if so, what is the most effective way of doing so? How does activated persuasion knowledge impact attitudes toward nudges and other interventions, and how does it impact their effectiveness?

\section{Conclusion}

We have argued that, as the application of behavioral public policy is gaining popularity, it is both important and timely to improve our understanding of public responses to behavioral interventions. We know that policy interventions, including behavioral ones like nudges, can trigger reactance, but we know very little about how, why and when this happens. To further our understanding of reactance and to unify existing insights into a coherent theoretical model, we propose the use of the PKM. Using the PKM allows us to move beyond studying nudges in isolation and to include the policy context. Using the PKM will also allow researchers to connect currently unconnected strands of scholarship from marketing, communication psychology and behavioral economics - thereby contributing to a field that has the potential to be truly interdisciplinary. A more coherent theoretical framework will also make it easier for policy-makers to distill practical lessons. In this way, we hope to contribute to closing the gap identified by Sanders, Snijders and Hallsworth (2018) between academic research on the one hand and practitioners' need for more and more systematic knowledge about effective and acceptable behavioral public policy interventions on the other.

\section{Disclosure}

The views expressed are those of the authors and do not necessarily reflect official positions of the Dutch Authority for the Financial Markets (AFM). 


\section{References}

Arad, A. and A. Rubinstein (2017), The people's perspective on libertarian-paternalistic policies. Retrieved from http://www.tau.ac.il/ aradayal/LP.pdf

Benartzi, S., J. Beshears, K. L. Milkman, C. R. Sunstein, R. H. Thaler, M. Shankar and Galing, S. (2017), 'Should governments invest more in nudging?' Psychological Science, 28(8): 10411055. https://doi.org/10.1177/0956797617702501

Brehm, J. W. (1966), A theory of psychological reactance. Oxford, England: Academic Press.

Brehm, J. and S. Brehm (1981), Psychological reactance. A theory of freedom and control. New York: Academic Press.

Campbell, M. C. and A. Kirmani (2008), 'I know what you're doing and why you're doing it: The use of persuasion knowledge model in consumer research', In C. P. Haugtvedt, P. M. Herr and F. R. Kardes (Eds.), Handbook of consumer psychology (pp. 549-574). New York: Taylor \& Francis Group

Clee, M. A. and R. A. Wicklund (1980), 'Consumer Behavior and Psychological Reactance', Journal of Consumer Research, 6(4): 389-405.

Diepeveen, S., T. Ling, M. Suhrcke, M. Roland and T. M. Marteau (2013), 'Public acceptability of government intervention to change health-related behaviours: a systematic review and narrative synthesis', BMC Public Health, 13(1): 756. https://doi.org/10.1186/1471-2458-13-756

Felsen, G., N. Castelo and P. B. Reiner (2013), 'Decisional enhancement and autonomy : public attitudes towards overt and covert nudges', Judgment and Decision Making, 8(3): 202-213. https://doi.org/10.1177/2332858416674007

Friestad, M. and P. Wright (1994), 'The Persuasion Knowledge Model: How people cope with persuasion attempts', Journal of Consumer Research, 21(1): 1-31. https://doi.org/10.1086/ 209380

Hedlin, S. and C. R. Sunstein (2016), 'Does active choosing promote green energy use? Experimental Evidence', Ecology Law Quarterly, 43(1): 107-141. https://doi.org/10.2139/ssrn.2624359

Jachimowicz, J. M., S. Duncan and E. U. Weber (2017), When and why defaults influence decisions: A meta-analysis of default effects. Retrieved from https://papers.ssrn.com/sol3/papers.cfm? abstract_id=2727301

Jung, J. Y. and B. A. Mellers (2016), 'American attitudes toward nudges', Judgment and Decision Making, 11(1): 62-74. Retrieved from http://ideas.repec.org/a/jdm/journl/v11y2016i1p6274.html

Krijnen, J., D. Tannenbaum and C. R. Fox (2018), 'Choice Architecture 2.0: Behavioral policy as a social interaction', Behavioral Science \& Policy. In press.

Loewenstein, G., C. Bryce, D. Hagmann and S. Rajpal (2014), 'Warning: You are about to be nudged'. SSRN Electronic Journal. https://doi.org/10.2139/ssrn.2417383

Pavey, L. and P. Sparks (2009), 'Reactance, autonomy and paths to persuasion: Examining perceptions of threats to freedom and informational value', Motivation and Emotion, 33(3): 277290. https://doi.org/10.1007/s11031-009-9137-1

Petrescu, D. C., G. J. Hollands, D. L. Couturier, Y. L. Ng and T. M. Marteau (2016), 'Public acceptability in the UK and USA of nudging to reduce obesity: The example of reducing sugar-sweetened beverages consumption', PLOS ONE, 11(6): 1-18. https://doi.org/10.1371/journal. pone.0155995

Rains, S. A. (2013), 'The nature of psychological reactance revisited: A meta-analytic review', Human Communication Research, 39(1): 47-73. https://doi.org/10.1111/j.1468-2958.2012.01443.x

Rebonato, R. (2014), 'A critical assessment of libertarian paternalism', Journal of Consumer Policy, 37(3): 357-396. https://doi.org/10.1007/s10603-014-9265-1

Reisch, L. A. and C. Sunstein (2016), 'Do Europeans like nudges'? Judgment and Decision Making, 11(4): 310-325. https://doi.org/10.1017/СBO9781107415324.004 
Reiter, P. L., A. L. McRee, J. K. Pepper and N. T. Brewer (2012), 'Default policies and parents' consent for school-located HPV vaccination', Journal of Behavioral Medicine, 35(6): 651657. https://doi.org/10.1007/s10865-012-9397-1

Sanders, M., V. Snijders and M. Hallsworth (2018), 'Behavioural science and policy: where are we now and where are we going?' Behavioural Public Policy, 2(2): 144-167.

Steffel, M., E. F. Williams and R. Pogacar (2016), 'Ethically deployed defaults: Transparency and consumer protection through disclosure and preference articulation', Journal of Marketing Research, 53(5): 865-880. https://doi.org/10.1509/jmr.14.0421

Sunstein, C. R. (2017), 'Nudges that fail', Behavioural Public Policy, 1(1): 4-25. https://doi.org/10. 1017/bpp.2016.3

Tannenbaum, D., C. R. Fox and T. Rogers (2017), 'On the misplaced politics of behavioural policy interventions’, Nature Human Behaviour, 1(7): 130. https:/doi.org/10.1038/s41562-0170130

Wright, P. (1986), 'Presidential Address Schemer schema: consumers' intuitive theories about marketers' influence tactics'. In R. J. Lutz (Ed.), Advances in Consumer Research, 13 (pp. 1-3). Provo, UT: ACR. Retrieved from http://www.acrwebsite.org/volumes/5947/volumes/v13/NA-13 